\title{
Status of Agricultural Statistics in Sudan
}

\author{
Nuha Mohamed Elamin Ahmed*, Mawahib Elsaied \\ Central Bureau of Statistic, Ministry of Agriculture, Sudan
}

Copyright $\bigcirc 2017$ by authors, all rights reserved. Authors agree that this article remains permanently open access under the terms of the Creative Commons Attribution License 4.0 International License

\begin{abstract}
Agriculture is playing a very important role in the Sudan economy of the country as more than 70 per cent of the population is engaged directly or indirectly in this activity. Sudan earns 45 per cent of its GDP from Agriculture. The current paper presents evolution of statistical activities and setting up of its institution is taken up since 1903. The objectives of the survey were: To estimate the average yield per feddan and consequently estimate the total production of sorghum; to estimate the harvested area depending on response from the selected farmers by identifying planted and harvested area; and also the same sample or a sub sample can be used to collect information on cost of production and marketing of agricultural products. The survey design used was stratified two stage random sample with uniform sampling fraction (proportionate allocation). For collection of data the agriculture sector in the country was divided into "Irrigated" and "Rainfed" sectors. Rainfedsector was further divided into "mechanized" and "traditional" sectors for the purposes of sampling designs. The country prepares Balance Sheet Cereal of and has a methodology for assessment of Food and Nutrition Security. The paper also outlined the existing Market Information System for Crop and Livestock.
\end{abstract}

Keywords Agricultural Information System, Methods of Collecting Agricultural Statistics, Cereal Balance Sheet, Food Security, Agricultural Products and Livestock Marketing

\section{Introduction}

Agriculture is playing a very important role in the Sudan economy; as more than 70 per cent of the population engaged directly or indirectly in this activity. Despite its diminishing contributions in the overall exports earnings, after the discovery and export of oil in the late $90 \mathrm{~s}$, agriculture share in GDP still represents about 45 per cent [1]. Such an essential activity needs an efficient information system that provides decision makers, planners, researchers and data users with appropriate, accurate and timely data. The agricultural information system must fulfill the following:-
1. Identify the information required for the most important and public decisions and specify the kinds of information that deserve highest priority.

2. Utilize methods and means of collecting, processing, analyzing, and presenting data that meet reasonable standards of accuracy, coverage and timeliness, while at the same time try to minimize financial and human costs.

3. Have institutional structure which brings users and suppliers of information in a continuous dialogue and which is able to adapt itself to the changing demands of information and modern methodologies for generating it.

Despite the general perception and understanding of the importance of information system by decision makers, politicians, planners, and most categories of data users, but still there is a wide gap between the understanding and adoption and application in reality, and in fact the standard of agricultural statistics is even deteriorating in recent years.

\section{Historical Background of Agricultural Statistics in Sudan}

Data collection in the agricultural sector was started in the beginning of $20^{\text {th }}$ century, with the establishment of department of agriculture and veterinary services, followed by irrigation. The department of statistics evolved as a division in 1903 and developed into department in 1953 and became a central bureau of statistics in the late $80 \mathrm{~s}$.

The agricultural economics and statistics section within the ministry of agriculture was established in 1958. It started with a very limited numbers of officials with economic and agricultural background.

In the early $60 \mathrm{~s}$, the division received a technical support in the field of agricultural statistics, and international expert was deployed to assist the division to develop and adopt objective methods of data collection, analysis and publication. Theoretical and practical training courses were conducted in area measurement and crop cutting experiments. Sudan is considered as one of the countries in Africa and the Arab world that have applied crop cutting experiment very early to estimate the sorghum yield. The first specialized 
agricultural statistics bulletin was published 1960/61, containing information on area, production and average yield of the main crops by centre of production, type of irrigation and administrative setup. Also rain fall data was included in this bulletin. This series of annual bulletins continued till $1969 / 1970$. In 1970/1971, it was substituted by the agricultural year book, which was on the same line to the bulletin, but included more detailed information of the main crops, rainfall and some information of livestock. In mid 80s other publications were issued such as the current agricultural statistics bulletin (CAS) and agricultural situation and outlook. These publications were meant to give supplementary information for the data included in the yearbook or to bridge the gap between two successive issues of the agricultural year book.

The agricultural division was upgraded to administration of agricultural economics and statistics, under the umbrella of the general administration of agricultural planning and economics. During 1990/91 the administration received financial and technical support through the agricultural planning and statistics project financed by USAID. This period witnessed trials for constructing an area sampling frame.

In 1993 the agricultural statistics a evolved as an independent administration.

In 1996 within the new structural setup in the ministry of agriculture, a general administration of information and statistics was established comprising three administration namely agricultural statistics, computer, documentation and agricultural economics. But in 2001, due to the institutional reform undertaken by the ministry of agriculture, the agricultural statistics administration was changed to the general directorate of planning.

After the implementation of the federal system in Sudan, data collection, analysis and publication was entrusted to the state ministries of agriculture, while the national agricultural schemes(Gezira, Rahad, New Halfa and Suki) were responsible for producing their own agricultural data. The role of agricultural statistics at the federal level was confined to training, technical support, co-ordination and publication of the agricultural data at the country level.

\section{Methods of Collecting Current Agricultural Statistics}

Methods of data collection may differ from one agricultural sector to another based on type of irrigation; so it is better to have an idea about the different agricultural sectors in the country. Agriculture in Sudan can be divided into two main sectors:

\section{a) The Irrigated Sector}

This sector includes areas irrigated from the River Nile and its tributaries using pumps, gravities, floods and from seasonal streams. Areas irrigated by pumps from bores (mataras) are considered as a part of this sector.

\section{b) Reinfed Sector}

In this sector the source of irrigation is rains. Based in using machineries in land preparation and harvesting; the reinfed sector is further sub divided into two sub sectors:

1. Mechanized reinfed sector: This sector is characterised by large size of holdings and machines are used in lan preparation and harvest (fully or partially), sizable portion of the mechanized sector is demarcated into schemes of regular shape of 1000 and 1500 feddans. Part of this sub sector is un-demarcated and the size of holding can range from less than 100 feddans to a few thousands (up to 5000).

2. Traditional reinfed sector: This sector includes areas mainly in western and southern Sudan where no machinery is applied and traditional methods of cultivation (agricultural tools) are practiced, but besides this, small holdings (roughly up to 50 feddans) where machinery is used in land preparation and partially in harvesting are considered as part of the traditional sector.

\section{Methods of Collection Agricultural Data in the Irrigated Sector}

\section{National Schemes}

In the national schemes a proper crop rotation system is followed, where each crop is planted in a separate piece of land, a number and definite size of feddans. It usually includes tenancies with equal sizes. The layout of the canalization system facilitates the estimation of planted areas under each crop. Accordingly, the statistics of area planted is considered accurate and reliable. The estimation of yield is based on sample survey from where crop-cutting method is conducted. For example Gazira scheme, the statistics division of the agricultural planning administration carries an annual survey to estimate yields of the main crops (sorghum, wheat, groundnuts and cotton). Per the administration interest to have information at the block level, all blocks are included, as the first stage of selection starts at the tenancy level. In scheme, 36 tenancies were selected from each block resulting 3.2 per cent based on the planted area, in a sample size of 40032 tenancies. The sample design adopted is a multi-stage random sample.

In the first stage of applying systematic random selection method, three canals (Turaa) were selected from each block, representing the start, middle and the end of the major canal. In the second stage, from each selected canal three numbers are selected applying simple systematic random selection, also representing the start, middle and the end of each number. At the third stage, three farmers are randomly selected from each selected number, one at the start, one at the middle and one at the end. At the region of the last stage, 3 plots of $2 * 2$ meters are randomly selected at the beginning, the middle and the end of the tenancy. Then the top portions of the crop were harvested, threshed and weighted, the yield 
weight was estimated by calculating the weighted average. At the same time paroled estimation which is mainly based on weekly records of the agricultural inspectors was prepared by the agricultural administration. Both estimates were submitted to the top administration of the scheme.

To avoid duplication and contradiction; objective method was adopted by the planning administration to improve this job with more facilities and financial capability.

The other national schemes (Rahad, New Halfa, Suki) are using more or less similar procedures of estimation, but Gezira scheme is more experienced in this aspect and its coverage and persistence is better.

\section{Other Irrigated Agricultural Schemes}

The state ministries of agriculture are responsible for generating the agricultural statistics of the irrigated sector in that state. Although these schemes are having their own agricultural rotation and somewhat similar canalization like the national scheme, but they rarely follow objective method of estimation. The data of area planted and area harvested has got good degree of accuracy, and usually there is a plan for targeted area and a close follow up at area of crop planted and areas to be harvested. At the early crop maturing stage yields are estimated based on eye estimates, and then refined from acetous records of threshers or combine harvesters at harvest time for crops like sorghum, wheat, broad bean where these crops are harvested either fully or partially by combine harvesters or threshers. The accuracy of yield figures can be considered acceptable, due to the procedure adopted for collecting agricultural data mainly for food crops in River Nile state.

According to the administrative division in the state, there are six localities. At each locality there is an agricultural inspector, assisted by new graduates of agriculture. They are located at administrative unites of particular locality. Each locality has an average of about 10 basic units. Each assistant inspector is responsible to collect data from his units by interviewing farmers and through his own observations, weekly reports are submitted from each locality starting from the time of land preparation till the time of harvest, giving information about areas, performance of the crop yields and factors affecting the crop, rainfall, number of irrigations, application of fertilizer, number of weeding, pests, and diseases etc.... At the time of harvest, the inspector tries to record the production by following the combined harvesters and threshers in the field. The agricultural planning administration with in the ministry of agriculture at River Nile state is responsible to prepare a weekly report reflecting the agricultural situation at state level.

\section{Rain-fed Mechanized Sector}

\section{Estimation of Planted Area}

The preliminary estimates of area depend to a large extent on the annual renewal records of the schemes as the farmers are supposed to pay rent before beginning of the season. Information of rain fall, prices, and information from farmers are supplemented and refined.

Usually during September; a team from mechanized farms co-operation (MFC) visits all scheme areas to estimate the planted area either by interviewing the farmers or the manager of the scheme or by eye estimation by the members of the team. In November and December, depending on the availability of funds and transportation facilities, the teams estimate the areas to be harvested and the expected yield by subjective methods (eye estimation). The federal administration of agricultural statistics of the ministry of agriculture in collaboration with state ministries of agriculture used to carry crop cutting surveys to estimate the yield of sorghum. The intensity of coverage and timeliness of these surveys depend considerably on the availability of financial resources. The coverage of the surveys in season $05 / 2006$ was the best during the last 15 years as it covered Gedaref, Damazin, S. Kordofan, Sennar, White Nile and Renk. Gedaref being the largest area was chosen as an example to explain the sampling procedure of the crop cutting survey.

\section{Objectives of the Survey}

1. To estimate the average yield per feddan and consequently estimate the total production of sorghum.

2. To estimate the harvested area depending on response from the selected farmers identifying planted and harvested area.

The same sample or a sub sample can be used to:

1. Collect information on cost of production.

2. Marketing of agricultural products.

\section{Sampling Design and Sample Size}

The survey design followed was stratified two stage random sample method with uniform sampling fraction (proportionate allocation). The producing centre was considered as in domain and a sampling error of 5 per cent of the average yield was contemplated. For the specified degree of accuracy, it was decided that 1000 experiments to be conducted in Gedaref. Blocks were considered as the main strata and sections within blocks sub strata. The first stage of sampling and number of farms (selection) were selected randomly from each section with in each block. This number is proportionate to the size area sown in that section. In the second stage of selection, two plots were randomly selected within each selected farm, with a size of a plot of $5 * 5$ meters $=1 / 168$ feddans. The selected plots were harvested, the number of heads was recorded and weighted wet and dry, I and the grain weighted. Simple weighted averages together with variance and sample errors were computed to calculate the average yield per feddan with confidence limits of the total production expected for each section and block, and accordingly the weighted average together with the maximum and minimum yield expected at the level of the producing center (Gedaref) [2]. 
Table 1. shows the area planted, area in sample, sample size, and actual area harvested:

\begin{tabular}{|c|c|c|c|c|c|}
\hline \multicolumn{6}{|c|}{ Crop-cutting on sorghum season 2005/2006: } \\
\hline \multicolumn{5}{|c|}{ Area covered, sample size, and the actual area harvested. } & \\
\hline \multicolumn{6}{|l|}{ Area in (000) feddans } \\
\hline \multirow[t]{2}{*}{ State } & Area & Area & \multicolumn{2}{|c|}{ Sample size } & Actual area \\
\hline & planted & in sample & Farmers & Plots & harvested Feddan \\
\hline Gedaref & 4567 & 422 & 500 & 1000 & 6 \\
\hline Sennar & 2209 & 104 & 200 & 400 & 2.4 \\
\hline Blue Nile & 684 & 119 & 151 & 302 & 1.8 \\
\hline White Nile & 1491 & 60 & 200 & 400 & 2.4 \\
\hline Renk & 477 & 136 & 200 & 400 & 2.4 \\
\hline Northern Kordofan & 970 & 7 & 521 & 1042 & 6 \\
\hline Southern Kordofan & 2192 & 166 & 482 & 964 & 5.9 \\
\hline Total & 12590 & 1014 & 2254 & 4508 & 26.9 \\
\hline
\end{tabular}

\section{Methods of Data Collection in the Traditional Rainfedsector}

As this sector is characterized by small size and scattered holdings, with mixed cropping pattern and shift cultivation, the data collection is problematic and its accuracy is questionable. In the $80 \mathrm{~s}$ regular surveys (pre-harvest and post-harvest) were conducted in most part of western Sudan where traditional agriculture is very common. Technical and financial support were provided through projects by receiving financial support from foreign organization or countries e.g. Savanah project, Jebel Marra project, Kordofan development project. Most of these projects are not functioning since late $80 \mathrm{~s}$ and early $90 \mathrm{~s}$, which led to irregularity in conducting these surveys, Drop in the coverage and accuracy is due to shortage in funds, transportation, facilities, equipment, and well trained staff. Also the late disputes and insecurity problems in Darfur hindered the activity of data collection. In most cases, either no survey carried or only one survey during the period pre-harvest or post-harvest was conducted. As an example for this sector considered, the post-harvest survey in North Darfur in season 05/2006 is considered.

\section{Sample Design}

A two stage stratified sample was adopted. The state was divided into 18 administrative units. From administrative unit (1-2) villages or towns were randomly selected taking into consideration the density of population, geographic locations and the economic situation of the population. 33 localities (village or town) were selected and from each selected locality 10 farmers were randomly selected and interviewed and the information was recorded in a questionnaire designed to fulfill this objective. The questionnaire contains information about seeds, agricultural operations, area planted, area harvested, yield, etc...
This information is supplemented from key information in different areas. Due to insecurity and limitation in funds the size of the sample is small and no statistical indicators are calculated, so the results of the survey should be taken with same precautions.

\section{Cereal Balance Sheet}

The report of FAO/WFP crop and food supply assessment mission included a very import table which reflects the national cereal supply / demand situation [3].

The format of the table is as follows:

\begin{tabular}{|c|c|l|l|l|l|l|}
\hline & $\begin{array}{c}\text { total } \\
\text { cereal }\end{array}$ & rice & Sorghum & Millet & wheat & maize \\
\hline $\begin{array}{c}\text { Availability } \\
\text { Opening } \\
\text { stock } \\
\text { production }\end{array}$ & & & & & & \\
\hline Utilization & & & & & & \\
\hline Food & & & & & & \\
Feed & & & & & & \\
Seed & & & & & & \\
Post- harvest & & & & & & \\
losses & & & & & & \\
Export & & & & & & \\
Closing & & & & & & \\
stock & & & & & & \\
\hline Commercial & & & & & & \\
imports & & & & & & \\
\hline
\end{tabular}

\section{Availability}

It's the sum of the opening stock and the production of the current season.

\section{Opening Stock}

It's usually the closing stock from the previous season, but 
it may be adjusted if new information is available in agencies like strategic reserve.

\section{Production}

It's the estimated production of the different cereals.

\section{Utilization}

Comprises human consumption, livestock consumption, seeds for the next season, post-harvest loses, export and closing stock.

\section{Food}

The human consumption estimation is based on the estimation of the population at mid-year of the season in question (e.g. 05/2006), multiplied by per capita cereal consumption. The estimation of population depends on extrapolation from the last population census taking into consideration other factors like number of returnees, refuses....etc.

Due to the absence of reliable data on per capita consumption as this requires regular and firmly surveys covering all regions, FAO estimated to use per capita consumption as $146 \mathrm{Kg}$ in Northern Sudan, and $85 \mathrm{Kg}$ in southern Sudan. These figures have been reached taking in consideration regional differences in diets, food production as availabilities historical trends, and conditions created by ongoing civil conflicts.

The per capita consumption of $146 \mathrm{Kg}$ consists of $83 \mathrm{Kg}$ sorghum $11 \mathrm{Kg}$ millet $49 \mathrm{Kg}$ wheat, $2 \mathrm{Kg}$ rice and $1 \mathrm{Kg}$ maize.

Seed requirement calculation are based on the forecast of the area of cereals for the coming season multiplied by used seed rate for each cereal crops: $5 \mathrm{Kg}$ of sorghum/fed, $2 \mathrm{Kg}$ of millet/fed, $5 \mathrm{Kg}$ of wheat/fed, $7 \mathrm{Kg}$ of maize/fed and $3 \mathrm{Kg}$ of rice/fed. These rates are based on MOA recommendations and farmers stated practices and are within the range of rates used in similar environments elsewhere.

Post-harvest losses may differ from one season to another according to production, availability and cost of labor, prices of the crop, usually these are estimated in the range of 7-15 per cent, as no comprehensive survey has been carried.

\section{Export}

The only exportable cereal is sorghum and the quantities exported are marginal as our prices are not compatible with international prices. The quantities to be exported are estimated taking into consideration the internal production, previous trends and production, political and economic relation with the neighboring countries that consume sorghum.

\section{Closing Stock}

It's calculated considering all the above mentioned items and the quantities of cereals expected to be imported.

\section{Commercial Imports}

The increasing demand for wheat due to urbanization and change in food habits has caused a substantial increase in the import of wheat. The estimation of wheat imports is based on trend from previous years and the production of wheat in the country and to some extent the production of other cereal crops.

The ministry of agricultural economics and planning of MOA presents cereal balance sheet on the same pattern as the (Crop and Food Security Assessment Mission- CFSAM) balance sheet. The figures are consistent with figures in CFSAM report. The ministry relied on human consumption estimation from the consumption survey that covered all states. The field surveys took place in 2002, while the data was analyzed and published in 2005. There was no significant difference in per capita consumption of wheat, millet, rice, and maize in the two reports, but per capita consumption of sorghum registered a remarkable difference (about 45 per cent less than the FAO estimate). Hence there is under estimation by MOA. If this was true, we would not practically we would not have any food deficit at national level and probably our storage facilities will not be enough to store the cress quantities. Some of the states in central and western Sudan used to prepare cereal balance sheet at the level of the state following the same per capita cereal consumption.

\section{Food Security and Nutrition Assessments Methodology (WFP)}

The methodology adopted by the World Food ProgramWFP for calculating food access shortfalls as the difference between expected food consumption requirement of people or household in any geographic area or population group and what they can provide for themselves without adopting distress strategies. According to the global standard the amount that households need to consume to live an active and healthy live is estimated at $2100 \mathrm{real} /$ per person /day. This amount could be subjected to adjustment due to factors like temperature, activity level and health/ nutrition condition, age, sex, distribution if data is available. The difference between the two above mentioned components excluding households consuming more than 2100 real/ person / day provides an estimate of the percentage of people and their average food deficit for a given location and demographic profile. These estimates are further extrapolated over similar agro- ecological zones and demographic profiles give the overall scope of the food deficits for various population groups. Accordingly, the emergency food needs to be met with international assistance were calculated taking into consideration of other factors like 
the national response capacity, changes in economic security situation, and level of external assistance provided during past similar year. WTP also considers the assistance rendered by other international or national agencies (Zahal - S.R.C) to address some of the food deficits from the own resources.

CFSAM relied to a large extent on primary or secondary food security analysis undertaken by national and international institutions within the country plus the missions' observations during the field visits, stakeholders' consultations and methodological reviews. In addition to different data sources, the mission mainly relied on the findings of the multi-agency food security and nutrition assessments including Darfur Emergency Food \& Nutrition Survey (EFSNS) [4],

Annual Need Assessment (ANA) for the rest of the country plus other surveys on nutritional assessment of rural Kassala and Red sea state [5].

EFSNS target population covered what is defined by United Nations as crisis affected population (3.2 million), including internally displaced persons living in camps, out of camps, as well as residents. The sample design was a two stage cluster sample where a total of 101 clusters were selected from the whole region of Darfor, using a population proportionate to size method. Due to insecurity, 87 clusters were actually covered, and data was collected from 2090 $\mathrm{HHs}$, and 1943 children were measured, $25 \mathrm{HHs}$ were selected applying systematic sampling from early selected clusters where heads of H.H.s were interviewed and responses were recorded in the questionnaires designed for this purpose, and children 5 years were measured - and weighed.

A special community questionnaire was designed to supplement the information provided in HHs questionnaire where leaders, teachers, women, health workers were collectively interviewed.

Nutrition and Health data was analyzed by Effect of Protein- EP into TM version 6.04d software (version 2001). Tests for statistical significance a proportions were done using a chi-square test.

\section{Limitations of the Survey}

1. The results cannot be generalized to cover all Darfor regions, as it only targeted the needing populations.

2. The seasonal effect in terms of food consumption, dietary diverse and frequency is not captured, as the survey is a one-time exercise.

3. The inaccuracy in population estimation due to lack of reliable population data may have a bearing on the accuracy of the assessment.

ANA addresses only the food security situation but it doesn't cover most of the state where food deficit is expected. Although some effort was made to introduce new methodologies of data collection, the rapid assessment methodology is prevalent.

ANA is expensive and requires considerable funds and human resources.

ANA adopts a multi-agency approval that yields a considerable amount of data; part of it is neither thoroughly analyzed nor disseminated due to financial and technical constraints. Besides the effort exerted by WFP in assessing the food security and nutritional status in food deficit area, NGOs, our WN agency and the government are carrying out similar surveys, but it is necessary to unify these efforts or at least create collaboration among these agencies to avoid duplication and contradiction and to prioritize the activities.

\section{Marketing Information of Agricultural Products}

Reliable, accurate, and timely marketing information is essential component that assists decision makers, traders, farmers and consumers to make the right decision and contributes to a high marketing efficiency, reduces marketing cost and increases marketing margins. In Sudan growing demand for agricultural product and food items coupled with food shortages, under lined the need for efficient marketing system. Historically, even at the beginning of the $20^{\text {th }}$ century department of trade collects some prices since the $60 \mathrm{~s}$, the central bureau of statistics used to publish marketing information dealing mainly with different commodities including agricultural products in different regions in a publication known as internal statistics. Currently the bureau of statistics collects consumer prices to calculate the consumer price indices [6]. After the years of drought in 1983-1984, there was an increasing need for marketing information, not only for the government, but also for organizations and international bodies that were involved in the relief activities. An early warning unit was established and hosted in Relief and Recovery Commissioner (RRC) with technical and financial support from aboard. In the Mid 80 s, the department of agricultural economics carried a survey and published marketing information in a publication known as marketing costs and margins for selected agricultural commodities in Sudan.

The series of publication continued till the early $90 \mathrm{~s}$ and was interrupted due to lack of finance.

Recently this activity was resumed again but its continuity will depend to a large extent on the availability of funds.

Some cereal markets like Gedarif, Obied which were at one time under the umbrella of the central cereal market corporation used to collect daily prices of the main agricultural commodities (sesame, groundnut, sorghum, millet, gum Arabic, karkade, and water melon seeds.... etc.), and the quantities sold. At the project time, these cereal markets are controlled by the states and structurally they are under the ministries of finance. Gedaref and Elobied cereal market are the most developed ones and all the data is computerized and up to date.

Many other organizations whether public or international organizations (VAus united WFP) or a CGO, are collecting 
some marketing information. Most of agricultural planning administrations at the level of the state used to collect prices either on weekly or monthly bases. The strategic reserve authority receives daily information of prices of agricultural commodities mainly cereal from eleven different markets representing cereal production and consumption. A number of other institutions like the agricultural bank, the economic security administration were involved in price data collection of the main agricultural commodities but there is a little co-ordination or exchange of data among these different agencies.

\section{Livestock Marketing Statistics}

The coverage, timeliness and standard of livestock marketing statistics are even below the level of the marketing statistics of other agricultural commodities. At the time when the livestock marketing corporation was formed, the prices of livestock, quantities sold were collected, but after the corporation was dissolved, the standard of coverage of livestock statistics decreased drastically. At present very few livestock markets record prices and qualities of livestock sold, and even the registration takes place only for livestock which are exported.

\section{REFERENCES}

[1] Central Bureau of Statistics- National Accounts Department reports.

[2] Annual reports of Agricultural Statistics - Department of Agricultural Statistics, ministry of Agriculture, 2001-2006.

[3] FAO/ WFP Annual Reports.

[4] Multi-agency food security and nutrition assessments including Darfur Emergency Food \& Nutrition Survey (EFSNS) 2005.

[5] Annual Need Assessment (ANA) reports for the rest of the country plus other surveys on nutritional assessment of rural Kassala and Red sea state.

[6] Consumer Price Indices Reports, Central Bureau of Statistics, 2000-2010. 